\title{
A retrospective study on the prevalence of urinary tract infections in a tertiary care hospital in Sangareddy district of South India
}

\author{
Sowjanya Mendem¹, M. Vinyas ${ }^{2}$, Md Aqib Ali Faraz ${ }^{1 *}$, M. Vishwanath Swamy ${ }^{1}$, \\ Patil Shubham ${ }^{1}$
}

${ }^{1}$ Department of Pharmacy Practice, MNR College of Pharmacy, Sangareddy, Telangana, India

${ }^{2}$ Department of Pharmacology, MNR College of Pharmacy, Sangareddy, Telangana, India

Received: 14 June 2020

Accepted: 08 July 2020

*Correspondence:

Dr. Md Aqib Ali Faraz,

E-mail: aqibalifaraz@gmail.com

Copyright: () the author(s), publisher and licensee Medip Academy. This is an open-access article distributed under the terms of the Creative Commons Attribution Non-Commercial License, which permits unrestricted non-commercial use, distribution, and reproduction in any medium, provided the original work is properly cited.

\begin{abstract}
Background: Urinary tract infections (UTI) affect the portion of the urinary tract including kidneys, ureters, bladder, and urethra, and are among the commonly acquired nosocomial infections. Diagnosis based on the culture and sensitivity profile of the organism is highly beneficial for appropriate antimicrobial therapy of the individual.

Methods: A retrospective study of culture isolates obtained from urine samples from different departments of a tertiary care hospital was performed in the period January 2018 to March 2020 in the district of Sangareddy, Telangana, India.

Results: A total 204 samples of 1886 exhibited significant growth of organisms i.e., $\geq 10^{5}$ colony-forming units of bacteria per millilitre (CFU mL-1). The most common pathogen isolated was Escherichia coli (47.05\%), followed by Klebsiella pneumoniae (15.68\%), Staphylococcus aureus (10.78\%), Pseudomonas aeruginosa (10.78\%), Enterobacter spp. (7.84\%) and, Candida albicans (7.84\%). The presence of Gram-negative organisms was found to be more than Gram-positive organisms among the samples cultured. Resistance was found to be more towards Amoxicillin (57.14\%), followed by oxacillin (34\%), cefotaxime (23.62\%), clarithromycin (12.08\%), erythromycin $(12.08 \%)$, azithromycin $(9.34 \%)$, linezolid (3.84\%) and vancomycin $(2.19 \%)$.

Conclusions: Increasing levels of antimicrobial resistance by uropathogens emphasize the importance of therapy based on the culture and sensitivity of the organisms. Many uropathogens exhibit multi-drugs resistance. Regular surveillance and monitoring are useful in controlling the increasing resistance.
\end{abstract}

Keywords: Antimicrobial resistance, Bacteriuria, Prevalence, Urinary tract infections, Uropathogens

\section{INTRODUCTION}

Urinary tract infections (UTIs) affect any portion of the urinary tract, including the kidneys, ureters, bladder, and urethra. The occurrence of UTIs in adult males under the age of 50 is minimal and is 30 times more likely in women. ${ }^{1}$ UTIs acquired in a hospital account for $35 \%$ $45 \%$ of nosocomial infections. $2 \%-4 \%$ of these infections may lead to septicaemia, which can be life-threatening. ${ }^{2}$ Recurring UTI refers to more than two symptomatic episodes occurring over 6 months or more than three symptomatic episodes over 12 months. Asymptomatic bacteriuria treatment in patients with recurrent UTIs has been shown to increase the risk of subsequent symptomatic UTI episodes and is therefore not recommended. ${ }^{3}$

UTIs constitute a wide range of conditions caused by the presence of microorganisms in the urinary tract. These symptoms include asymptomatic UTI (bacteriuria with or without symptoms), symptomatic lower UTI or cystitis, and upper UTI or acute pyelonephritis. Cystitis is 
characterized by significant bacteriuria with pyuria and symptoms such as dysuria, new-onset urinary incontinence, lack of proper stream. Upper UTI or pyelonephritis is characterized by significant bacteriuria with pyuria, increased levels of markers of inflammation such as white blood cells (WBCs), C reactive protein and procalcitonin and clinical symptoms: fever, back pain, abdominal pain, and vomiting. ${ }^{4}$ Symptomatic UTIs are characterized by the presence of $\geq 105$ colony-forming units of bacteria per millilitre (CFU mL-1) in one urine sample along with the specific symptoms. ${ }^{5}$ This condition is further complicated by the fact that correct diagnosis relies on both the presence of symptoms and a positive culture of urine, although it is made without the benefit of culture in most outpatient settings. ${ }^{6}$

Treatment and diagnosis of UTI based on the clinical symptoms are not accurate and the diagnostic error rate can exceed $30 \%$. When laboratory procedures are applied, urine samples are the most dependant specimen type used to confirm the occurrence of UTI. ${ }^{7}$ Both gramnegative and gram-positive bacteria can be causative organisms for UTIs, in addition to certain fungi. The most important and common etiological agent is Escherichia coli or E.coli followed by Klebsiella pneumoniae, Staphylococcus saprophyticus, Enterococcus faecalis, Group B Streptococcus, Proteus mirabilis, Pseudomonas aeruginosa, Staphylococcus aureus, and Candida spp. ${ }^{8}$ Typically the most common source of infection comes from colonization of microorganisms in anus and perineum that passes via the urethra, so UTI pathogens are generally natural intestinal flora translocated to the urinary tract. ${ }^{9}$

Surveillance studies indicate increased resistance for both Gram-positive and Gram-negative bacteria, including $E$. coli, the most prevalent causative agent for urinary tract infections (UTIs). Broad access to inexpensive antimicrobial drugs results in rapid antimicrobial drug resistance (AMR) development, which is difficult to detect. Continuous monitoring of the use of these drugs is therefore often necessary. ${ }^{10}$ The preliminary choice of antimicrobial therapy is based on the patient's age group, prevalent pathogens, antimicrobial resistance trends in the practice area, and the patient's clinical condition. ${ }^{11}$

Since antimicrobial resistance is an unavoidable phenomenon, the prescription of correct antimicrobials with an accurate dose for the right duration of time can help improve the patients' quality of life. ${ }^{12}$ The study aims at finding the prevalence of UTIs in a given geographical location and determine the most prevalent organism and common antimicrobials in use. Proper diagnosis and treatment of UTI have a direct implication on the patients' health.

\section{METHODS}

A retrospective study was performed from January 2018 to March 2020 in the departments of general medicine, general surgery, Obstetrics, and Gynecology at MNR Medical College and Hospital in the district of Sangareddy, Telangana, India. A total of 1886 samples were studied, of which 204 samples have exhibited significant bacterial growth. (i.e $\geq 105 \mathrm{CFU} \mathrm{mL}-1$ ).

\section{Inclusion criteria}

- Age groups ranging between 21 to 60 years consisting of both male and female patients were included in the study.

\section{Exclusion criteria}

- The pediatric population was excluded.

The samples were cultured to isolate the pathogen and to determine the colony count. Standard laboratory methods were used for urine sample culture.

\section{Collection of samples}

The samples were collected using the clean-catch midstream technique as it is non-invasive and can be carried out easily. ${ }^{13}$

\section{Culture of the urine sample and antimicrobial sensitivity test}

The samples were cultured using calibrated loops in a semiquantitative method on MacConkey's and blood agar media. The traditional procedure for urine culture required $1 \mu$ l of urine, spread on a blood agar plate and MacConkey agar, and aerobically incubated for 24 hours at $35^{\circ} \mathrm{C} .^{14}$ Antimicrobial susceptibility pattern on Mueller-Hinton agar was measured using the KirbyBauer disc diffusion method. ${ }^{8}$ Findings were interpreted in compliance with the 2012 guidelines for the Clinical and laboratory standards institute (CLSI).

For further identification and susceptibility testing, samples with a colony count of $\geq 105$ colony forming units $(\mathrm{CFU} / \mathrm{mL})$ were deemed significant. Culture media and disc quality control were conducted using control strains from ATCC (american type culture collection). Antimicrobial discs were procured from HIMEDIA laboratories in Mumbai.

\section{Statistical analysis}

Statistical analysis was performed using SPSS version 25. The frequency of distribution of uropathogens and the difference between the age groups (21-30, 31-40, 41-50, 51-60) was calculated using the Chi-square test $\left(\chi^{2}\right)$ and p-values less than 0.05 were considered significant.

\section{RESULTS}

A total of 1886 samples were cultured during the period January 2018 to March 2020, of which 204 samples 
(10.81\%) showed significant bacterial growth. Of the 204 positive samples, $57(27.94 \%)$ belonged to male patients while $147(72 \%)$ positive samples belonged to female patients of different age groups. $182(89.21 \%)$ samples of the significant 204 samples have exhibited resistance to one or more antimicrobials.

The following organisms were isolated from the urine samples, E. coli, Klebsiella pneumoniae, Pseudomonas aeruginosa, Enterobacter spp., Staphylococcus aureus, and Candida albicans. The presence of uropathogens was more commonly noted in the age group of 31-40 years in both the genders. The most common pathogen isolated was E. coli $(47.05 \%)$, followed by Klebisella pneumoniae (15.68\%), Staphylococcus aureus (10.78\%), Pseudomonas aeruginosa (10.78\%), Enterobacter spp. (7.84\%) and Candida albicans $(7.84 \%)$ (Figure 1).

Table 1. Distribution of uropathogens among different age groups and genders.

\begin{tabular}{|c|c|c|c|c|c|c|c|c|c|c|c|}
\hline \multicolumn{2}{|c|}{ Age groups (in years ) } & \multicolumn{2}{|l|}{$21-30$} & \multicolumn{2}{|l|}{$31-40$} & \multicolumn{2}{|l|}{$41-50$} & \multicolumn{2}{|l|}{ 51-60 } & \multirow{2}{*}{$\begin{array}{l}\text { Chi-square } \\
\text { value }\left(\chi^{2}\right) \\
\text { (degrees of } \\
\text { freedom) }\end{array}$} & \multirow{2}{*}{$\begin{array}{l}\text { p- } \\
\text { value } \\
(0.05)\end{array}$} \\
\hline Isolates & Total & $\mathbf{M}$ & $\mathbf{F}$ & $\mathbf{M}$ & $\mathbf{F}$ & $\mathbf{M}$ & $\mathbf{F}$ & $\mathbf{M}$ & $\mathbf{F}$ & & \\
\hline E. coli. & 96 & $\begin{array}{l}7 \\
(7.29 \%)\end{array}$ & $\begin{array}{l}11 \\
(11.4 \%)\end{array}$ & $\begin{array}{l}15 \\
(15.625 \%)\end{array}$ & $\begin{array}{l}21 \\
(21.875 \%)\end{array}$ & $\begin{array}{l}7 \\
(7.29 \%)\end{array}$ & $\begin{array}{l}18 \\
(18.75 \%)\end{array}$ & $\begin{array}{l}3 \\
(3.125 \%)\end{array}$ & $\begin{array}{l}14 \\
(14.585 \%)\end{array}$ & $3.57(3 \%)$ & 0.311 \\
\hline $\begin{array}{l}\text { Klebsiella } \\
\text { pneumoniae }\end{array}$ & 32 & $\begin{array}{l}2 \\
(6.25 \%)\end{array}$ & $\begin{array}{l}6 \\
(18.75 \%)\end{array}$ & $4(12.5 \%)$ & $7(21.87 \%)$ & $\begin{array}{l}3 \\
(9.37 \%)\end{array}$ & $6(18.75 \%)$ & $1(3.12 \%)$ & $3(9.3 \%)$ & $0.37(3 \%)$ & 0.946 \\
\hline $\begin{array}{l}\text { Pseudomonas } \\
\text { aeruginosa }\end{array}$ & 22 & $\begin{array}{l}1 \\
(4.54 \%)\end{array}$ & $2(9.09 \%)$ & $2(9.09 \%)$ & $4(18.18 \%)$ & $1(4.5 \%)$ & $4(18.18 \%)$ & $2(9.09 \%)$ & $6(27.27 \%)$ & $0.321(3 \%)$ & 0.956 \\
\hline $\begin{array}{l}\text { Staphylococcus } \\
\text { aureus }\end{array}$ & 22 & $\begin{array}{l}1 \\
(4.54 \%)\end{array}$ & $\begin{array}{l}4 \\
(18.18 \%)\end{array}$ & $2(9.09 \%)$ & $6(27.27 \%)$ & $\begin{array}{l}1 \\
(4.54 \%)\end{array}$ & $4(18.18 \%)$ & $1(4.54 \%)$ & $3(13.63 \%)$ & $0.078(3 \%)$ & 0.994 \\
\hline $\begin{array}{l}\text { Enterobacter } \\
\text { spp. }\end{array}$ & 16 & $\begin{array}{l}1 \\
(6.25 \%)\end{array}$ & $\begin{array}{l}3 \\
(18.75 \%) \\
\end{array}$ & $2(12.5 \%)$ & $4(25 \%)$ & $\begin{array}{l}1 \\
(6.25 \%)\end{array}$ & $3(18.75 \%)$ & $1(6.25 \%)$ & $1(6.25 \%)$ & $0.485(3 \%)$ & 0.922 \\
\hline $\begin{array}{l}\text { Candida } \\
\text { albicans }\end{array}$ & 16 & $\begin{array}{l}1 \\
(6.25 \%)\end{array}$ & $\begin{array}{l}3 \\
(18.75 \%)\end{array}$ & $1(6.25 \%)$ & $5(31.25 \%)$ & $\begin{array}{l}2 \\
(12.5 \%)\end{array}$ & $2(12.5 \%)$ & $1(6.25 \%)$ & $1(6.25 \%)$ & $1.648(3 \%)$ & 0.648 \\
\hline Total & 204 & 13 & 29 & 26 & 47 & 15 & 37 & 9 & 28 & 1.613 & 0.656 \\
\hline
\end{tabular}

Numbers represent data and percentages are represented in brackets. The frequency of each uropathogen among different age groups was performed using the Chi-square test.

Table 2: A percentage representation of antimicrobial resistance exhibited by the uropathogens.

\begin{tabular}{|c|c|c|c|c|c|c|c|c|c|}
\hline Isolates & $\mathbf{N}(\mathbf{1 8 2})$ & AMX & OXA & CTZ & CLR & ERY & AZI & VAN & LNZ \\
\hline E.coli & $75(41.2 \%)$ & $42(56 \%)$ & $29(38.6 \%)$ & $16(21.3 \%)$ & $0(0 \%)$ & $0(0 \%)$ & $0(0 \%)$ & $0(0 \%)$ & $0(0 \%)$ \\
\hline $\begin{array}{l}\text { Klebsiella } \\
\text { pneumoniae }\end{array}$ & $32(17.5 \%)$ & $21(65.6 \%)$ & $14(43.75 \%)$ & $8(25 \%)$ & $4(12.5 \%)$ & $8(25 \%)$ & $7(21.8 \%)$ & $0(0 \%)$ & $0(0 \%)$ \\
\hline $\begin{array}{l}\text { Pseudomonas } \\
\text { spp. }\end{array}$ & $11(6.04 \%)$ & $7(63.6 \%)$ & $3(27.2 \%)$ & $1(9.09 \%)$ & $0(0 \%)$ & $1(9.09 \%)$ & $0(0 \%)$ & $0(0 \%)$ & $0(0 \%)$ \\
\hline $\begin{array}{l}\text { Enterobacter } \\
\text { spp. }\end{array}$ & $40(21.9 \%)$ & $21(52.5 \%)$ & $16(40 \%)$ & $14(35 \%)$ & $9(22.5 \%)$ & $6(15 \%)$ & $4(10 \%)$ & $4(10 \%)$ & $5(12.5 \%)$ \\
\hline $\begin{array}{l}\text { Staphylococcus } \\
\text { aureus }\end{array}$ & $24(13.1 \%)$ & $13(54.16 \%)$ & $0(0 \%)$ & $4(16.6 \%)$ & $9(37.5 \%)$ & $7(29 \%)$ & $6(25 \%)$ & $0(0 \%)$ & $2(8.3 \%)$ \\
\hline Mean \pm SD & $36.4 \pm 24.08$ & $58.37 \pm 5.88$ & $29.92 \pm 17.82$ & $21.39 \pm 9.65$ & $14.5 \pm 15.94$ & $15.65 \pm 11.81$ & $11.37 \pm 11.79$ & $2 \pm 4.47$ & $4.16 \pm 5.89$ \\
\hline
\end{tabular}

The results exhibited the presence of gram-negative organisms (E. coli, Klebsiella pneumoniae, Pseudomonas spp.) was higher than that of gram-positive organisms (Enterobacter spp, Staphylococcus aureus). The frequency of uropathogen isolates distribution among different age groups was found to be more in the 31-40 years group. $\left(\chi^{3}=1.613, \mathrm{p}\right.$-value=0.656) $($ Table1 $)$. E. coli and Klebsiella pneumoniae were found to be more prominent in this age group $(\chi 3=3.57, p$-value $=0.311$, $\chi 3=0.37$, p-value $=0.946$ respectively). Staphylococcus aureus was the common gram-positive organism $(10.78 \%)$, found in the $31-40$ years age groups of female patients $\quad(\chi 3=0.078, \quad p$-value $=0.994), \quad$ followed by
Enterobacter spp. and the isolates were found more in the age group of 51-60 ( $\chi^{3}=0.485, \mathrm{p}$-value $\left.=0.922\right)$. Isolates of Candida albicans was found to be more in the age group of $31-40$ years. $\left(\chi^{3}=1.648, p\right.$-value $\left.=0.648\right)($ Table $1)$.

The percentage of resistance to the prescribed antimicrobials is exhibited in Table 2. Resistance was exhibited mostly to amoxicillin $(57.14 \%)$, followed by oxacillin (34\%), cefotaxime (23.62), clarithromycin $(12.08 \%)$, erythromycin (12.08\%), azithromycin (9.34\%), linezolid $(3.84 \%)$ and vancomycin $(2.19 \%)$. E. coli, Klebsiella pneumoniae and Enterobacter spp. exhibited 
resistance greatly towards amoxicillin, oxacillin and cefotaxime, when compared to the other organisms and were found to have decreased resistance towards the other antimicrobials. Resistance patterns for Pseudomonas aeruginosa and Staphylococcus aureus were comparatively less, and these organisms exhibited maximum resistance towards amoxicillin (Figure 2).

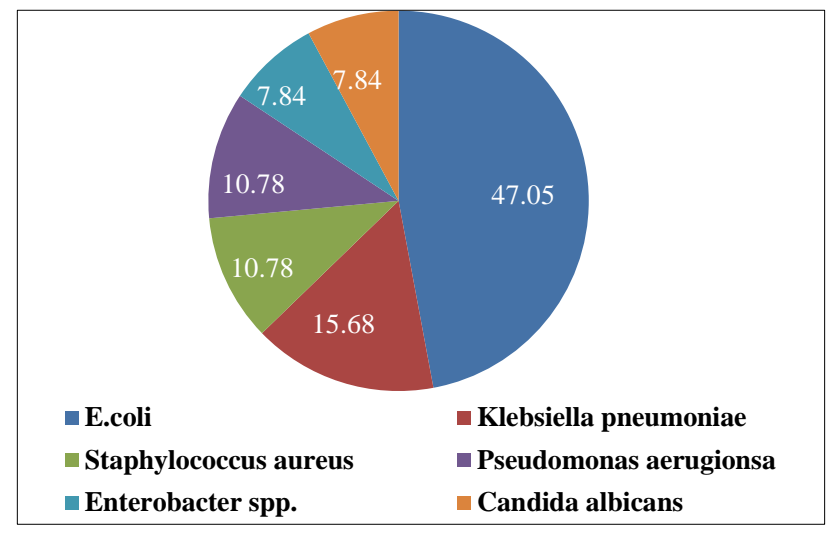

Figure 1: Distribution of various organisms in the population.

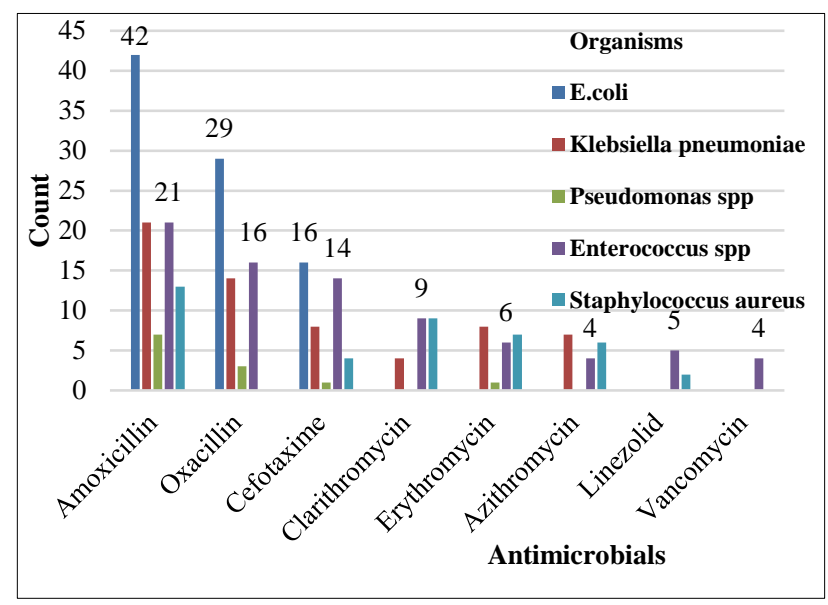

Figure 2: Antimicrobial resistance patterns of various organisms.

\section{DISCUSSION}

The current study focuses on the distribution of UTIs across both genders and various age-groups, as well as the resistance patterns exhibited by various uropathogens in response to the antimicrobials. The fraction of females was higher across all the age groups compared to the males due to the urethra's shortness and proximity to the anus, which makes it possible for bacteria to ascend across the urinary tract. ${ }^{15}$ More female patients were observed in the age group of 31-40 years followed by 4150 years. The risk factors for recurrent UTI in premenopausal sexually active women include the onset of symptoms briefly after sexual intercourse, the use of spermicides for contraception, the emergence of new sexual partners, the age of the first UTI, maternal history of UTI and the dysfunction in voiding. ${ }^{16}$ The least number of female patients was observed in the age group 51-60 years. Women in the youngest age group were found to have an increased probability of recurrent UTI as opposed to the older women. ${ }^{17}$

The most common pathogen isolated was E.coli (47.05\%), followed by Klebisella pneumoniae (15.68\%), Staphylococcus aureus (10.78\%), Pseudomonas aeruginosa (10.78\%), Enterobacter spp. (7.84\%) and Candida albicans $(7.84 \%)$ (Figure 1). Pathogenic E.coli is the key cause of UTIs acquired by the community (about $80-90 \%) .{ }^{18}$ E.coli and Klebsiella pneumoniae were the most commonly isolated pathogens in most studies. ${ }^{19}$

Antimicrobial resistance arising in the management of UTIs is a major public health concern. In the developing world, where there is a high degree of poverty, and inadequate hygienic practices, there is also a high prevalence of fraudulent and counterfeit medicines of dubious quality in consumption. ${ }^{20}$ Hence, the study of the prevalence of uropathogens and their antimicrobial susceptibility is essential in improving the prescription patterns of the antimicrobials.

In the present study, most organisms showed the highest resistance to amoxicillin (57.14\%), followed by oxacillin (34\%), cefotaxime (23.65), clarithromycin (12.08\%), erythromycin (12.08\%), azithromycin (9.34\%), linezolid $(3.84 \%)$ and vancomycin $(2.19 \%)$ (Table 2$)$. Vancomycin has shown the highest efficacy followed by linezolid, erythromycin, azithromycin, clarithromycin, and cefotaxime. Amoxicillin has shown to be the least efficacious drug followed by oxacillin in the current setting. Enterobacter spp. has proved to be resistant to almost all the antimicrobials used in the study. E.coli has exhibited the most resistance towards amoxicillin, oxacillin and cefotaxime, followed by Enterococcus spp. and Klebsiella pneumoniae. This resistance towards amoxicillin was exhibited by all the isolated organisms and similar patterns of resistance were exhibited towards oxacillin (Figure 2). This resistance to penicillin-like antimicrobials can be due to the production of extendedspectrum beta-lactamases by the pathogens. ${ }^{21}$

Proper and timely diagnosis of the UTIs is essential for improving the patients' quality of life, as well as combating various issues like antimicrobial resistance, reduction in the therapeutic costs, and proper prescription of antimicrobials. Antimicrobial resistance levels were particularly high in E.coli. ${ }^{22}$ Monitoring the prevalence of the UTIs in a geographical area over a given period is beneficial in guiding the treatment pattern thus leading to improved patient care.

The limitations of this study were that it was mostly carried under laboratory conditions and basic antimicrobials were only used. Tests of antimicrobial resistance are very critical for effective therapy and lowcost management. ${ }^{23}$ Specific antimicrobial resistance 
surveillance is critical for tracking resistance overtime at the state, national and international levels. ${ }^{24}$ Overall, this study focused on highlighting the prevalence of UTIs and the resistance patterns of various uropathogens to antimicrobials in Sangareddy.

\section{CONCLUSION}

It is always advised to prescribe medications following the results of culture sensitivity and urine analysis, especially in patients who are at a risk. Pre-menopausal women must take precautions as they are more prone to acquiring UTIs. E.coli prevalence was found to be more in all populations of men and women and amoxicillin resistance was very common among different antibiotics, which gives a clear idea of the resistance patterns of antibiotics in the area of Sangareddy. Hence, it is advisable to limit the prescription of Penicillin-like antibiotics and enhance prescription of combination drugs as a means to reduce the development of antibiotic resistance among various populations.

\section{ACKNOWLEDGMENTS}

Authors would like to thank MNR Research facilities and to V. Alagarsamy, Principal of MNR College of Pharmacy for their help in carrying out the study.

Funding: No funding sources Conflict of interest: None declared

Ethical approval: Not required

\section{REFERENCES}

1. Tan CW, Chlebicki MP. Urinary tract infections in adults. Singapore Med J. 2016;57(9):485-90.

2. Kamat US, Fereirra A, Amonkar D, Motghare DD, Kulkarni MS. Epidemiology of hospital-acquired urinary tract infections in a medical college hospital in Goa. Indian J Urol. 2009;25(1):76-80.

3. Storme O, Tiran Saucedo J, Garcia-Mora A, DehesaDávila M, Naber KG. Risk factors and predisposing conditions for urinary tract infection. Ther Adv Urol. 2019;11:19-28.

4. Daniel M, Szajewska H, Pańczyk-Tomaszewska M. 7-day compared with 10-day antimicrobial treatment for febrile urinary tract infections in children: protocol of a randomized controlled trial. BMJ Open. 2018;8(3):e019479.

5. Sekharan CB, Kumari KR, Kuwingwa EE, Kumar DD. Evaluation of the prevalence of urinary tract infection in females aged 6-50 years at Kinondoni District, Tanzania. Sci Int. 2017;5:42-6.

6. Arora G, Kaur P, Agrawal D. Urinary tract infection in women of rural population of Haryana: a rising problem. Int J Reprod Contracept Obstet Gynecol. 2016;5:4470-4.

7. Al-Naqshbandi AA, Chawsheen MA, Abdulqader HH. Prevalence and antimicrobial susceptibility of bacterial pathogens isolated from urine specimens received in rizgary hospital-Erbil. J Infect Public Heal. 2019;12:330-6.

8. Kalal BS, Nagaraj S. Urinary tract infections: a retrospective, descriptive study of causative organisms and antimicrobial pattern of samples received for culture, from a tertiary care setting. GERMS. 2016;6(4):132-8.

9. Setyorini H, Mardiana N, Tjempakasari A. Risk factors for urinary tract infection in hospitalized patients. BHSJ. 2019;2(1):4-8.

10. Taher I, Almaeen A, Aljourfi H, Bohassan E, Helmy A, El-Masry E, et al. Surveillance of antimicrobial resistance among uropathogens in Aljouf region northern Saudi Arabia. IJM. 2019;11(6):468-77.

11. Nimri L. Community-acquired urinary tract infections in a rural area in Jordan: Predominant uropathogens, and their antimicrobial resistance. WMC Micro Bio. 2010;1(9):WMC00660.

12. Mohapatra DP, Debata NK, Singh SK. Extensively drug-resistant and pandrug-resistant Gram-negative bacteria in a tertiary-care hospital in Eastern India: A 4-year retrospective study. JGAR. 2018;15:246-9.

13. Wilson ML, Gaido L. Laboratory diagnosis of urinary tract infections in adult patients. Clin Infect Dis. 2004;38(8):1150-8.

14. Price TK, Dune T, Hilt EE, Thomas-White KJ, Kliethermes S, Brincat $\mathrm{C}$, et al. The clinical urine culture: enhanced techniques improve detection of clinically relevant microorganisms. J Clin Microbiol. 2016;54(5):1216-22.

15. Minardi D, D'Angelo G, Cantoro D, Conti A, Muzzonigro G. Urinary tract infections in women: etiology and treatment options. Int $\mathrm{J}$ Gen Med. 2011;4:333-43.

16. Al-Badr A, Al-Shaikh G. Recurrent urinary tract infections management in women: a review. Sultan Qaboos Univ Med J. 2013;13(3):359-67.

17. Rich SN, Klann EM, Almond CR, Larkin EM, Nicolette G, Ball JD. Associations between antimicrobial prescriptions and recurrent urinary tract infections in female college students. Epidemiol Infect. 2019;147:e119.

18. Terlizzi ME, Gribaudo G, Maffei ME. UroPathogenic Escherichia coli (UPEC) infections: virulence factors, bladder responses, antimicrobial, and non-antimicrobial antimicrobial strategies. Front Micro Biol. 2017; 8:1566.

19. Beyene G, Tsegaye W. Bacterial uropathogens in urinary tract infection and antimicrobial susceptibility pattern in Jimma university specialized hospital, southwest Ethiopia. Ethiop J Health Sci. 2011;21(2):141-6.

20. Seifu WD, Gebissa AD. Prevalence and antimicrobial susceptibility of Uropathogens from cases of urinary tract infections (UTI) in Shashemene referral hospital, Ethiopia. BMC Infect Dis 2018;18(1):30.

21. He K, Hu Y, Shi JC, Zhu YQ, Mao XM. Prevalence, risk factors, and microorganisms of urinary tract infections in patients with type 2 diabetes mellitus: a 
retrospective study in China. Ther Clin Risk Manag. 2018;14:403-8.

22. Lee AC, Mullany LC, Koffi AK, Rafiqullah I, Khanam R, Folger LV, et al. Urinary tract infections in pregnancy in a rural population of Bangladesh: population-based prevalence, risk factors, etiology, and antimicrobial resistance. BMC Preg ChildB. 2020;20(1): 1 .

23. Beksac AT, Orgul G, Tanacan A, Uckan H, Sancak $\mathrm{B}$, Portakal O, et al. Uropathogens and gestational outcomes of urinary tract infections in pregnancies that necessitate hospitalization. Curr Urol. 2019;13(2):70-3.

24. Van der Donk CF, van de Bovenkamp JH, De Brauwer EI, et al., Antimicrobial resistance and spread of multidrug-resistant Escherichia coli isolates collected from nine urology services in the Euregion Meuse-Rhine. Plos One. 2012;7(10):e47707.

Cite this article as: Mendem S, Vinyas M, Faraz MAA, Swamy MV, Shubham P. A retrospective study on the prevalence of urinary tract infections in a tertiary care hospital in Sangareddy district of South India. Int J Reprod Contracept Obstet Gynecol 2020;9:3422-7. 